\title{
Efeito da aplicação de águas residuárias de suinocultura sobre a produção do milho para silagem ${ }^{1}$
}

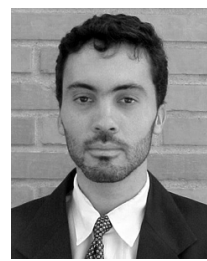

Wallisson da S. Freitas ${ }^{2}$, Rubens A. de Oliveira ${ }^{3}$, Fernando A. Pinto ${ }^{4}$, Paulo R. Cecon ${ }^{5}$ \& João C. C. Galvão ${ }^{6}$

\author{
1 Parte da Dissertação de Mestrado do primeiro autor, trabalho financiado pela FAPEMIG; \\ 2 Rua Geninho Lentine, 135, CEP 36571-000 Viçosa, MG. Fone: (31) 3892-5089. E-mail: wallfreitas@yahoo.com.br (Foto) \\ ${ }^{3}$ DEA/UFV. Av. Ph Rolfs s/n, Viçosa, MG. Fone: (31) 3899-1909. E-mail: rubens@ufv.br \\ 4 DEC/UFV. Fone: (31) 3899-3029. E-mail: ferpinto@ufv.br \\ ${ }^{5}$ DPI/UFV. Fone: (31) 3899-1781. E-mail: cecon@ufv.br \\ 6 DFT/UFV. Fone: (31) 3899-1167. E-mail: jgalvao@ufv.br
}

Protocolo 31 - 22/3/2002 - Aprovado em 6/2/2004

\begin{abstract}
Resumo: Este trabalho foi conduzido com o objetivo de se avaliar o efeito da aplicação de quatro lâminas de água e águas residuárias de suinocultura, bruta e peneirada, sobre os componentes de produção da cultura do milho (Zea mays L.) para silagem. Foram instalados 24 lisímetros de percolação, sendo que em 8 deles se aplicou água (A), em 8 água residuária bruta (ARB) e nos demais água residuária peneirada (ARP). As lâminas aplicadas correspondiam a 0,5, 1,0, 1,5 e $2,0 \mathrm{ET}_{0}$. A colheita foi realizada 140 dias após o plantio, quando se avaliaram os componentes de produção: altura de plantas, peso, altura, produtividade e índice de espigas e produtividade de matéria verde. As produtividades médias de matéria verde nos tratamentos com ARB e ARP foram equivalente a 45 e $46 \mathrm{t} \mathrm{ha}^{-1}$, cerca de 51 e $52 \%$ superiores à testemunha, respectivamente. A aplicação das águas residuárias de suinocultura aumentou significativamente os valores de altura de plantas, índice de espigas, altura de espigas e peso de espigas. Em geral, o peneiramento das águas residuárias e as diferentes lâminas aplicadas não afetaram os parâmetros de produção do milho para silagem.
\end{abstract}

Palavras-chave: fertirrigação, águas residuárias de suinocultura, lisímetro, Zea mays, $L$

\section{Effect of swine wastewater application on corn production for silage}

\begin{abstract}
This work was carried out with the objective of evaluating the effect of four depths of water and swine wastewater-gross and after sieving, on production of corn (Zea mays, L.) for silage. Water was applied in eight lysimeters, in other eight gross swine wastewater (ARB) was applied and the sieved pig wastewater (ARP) on the other eight. The depths applied corresponded to 0.5, 1.0, 1.5 and 2.0 times of the reference evapotranspiration. The production components, height of the plants, height of spikes, spike index, productivity of spikes and productivity of green matter were evaluated 140 days after sowing. The mean productivities of green matter in the treatments with ARB and ARP were equivalent to 45 and $46 \mathrm{t} \mathrm{ha}^{-1}$, corresponding to, respectively, 51 and $52 \%$ higher than the productivity in the water treatment. The application of swine wastewater increased the height of plants, spike index, height of spikes and weight of spikes. In general, the sieving of swine wastewater and the water depth did not affect the production components of the silage corn.
\end{abstract}

Key words: fertirrigation, swine wastewater, lysimeter, Zea mays, L.

\section{INTRODUÇÃO}

A disposição de águas residuárias de animais no solo é muito usada no mundo, principalmente na Europa e nos Estados Unidos, tanto como técnica de tratamento por escoamento superficial quanto na fertilização de solos cultivados. No Brasil, ela tem sido muito usada na fertirrigação de culturas exploradas em regiões produtoras de suínos e bovinos, criados em sistema de confinamento.

A intensificação da criação de suínos em regime de confinamento na Zona da Mata Mineira, que responde por cerca de
$30 \%$ da suinocultura tecnificada do Estado, aumentou consideravelmente a produção de águas residuárias. Muitos suinocultores estão reduzindo a quantidade de sólidos totais dessas águas por meio de peneiramento, sendo a massa retida usada na alimentação de bovinos e o efluente armazenado em lagoas de estabilização, podendo ser usado na fertirrigação de diversos cultivos.

A restrição de área para exploração agrícola, devido ao relevo bastante acidentado, tem ocasionado a disposição de grandes quantidades de águas residuárias na fertirrigação de 
forrageiras e de cultivos anuais, o que pode estar ocasionando contaminação de águas subterrâneas e desequilíbrio no solo e nas plantas. Estudos simulando aplicações de diferentes dosagens podem oferecer subsídios a técnicos e produtores envolvidos no processo.

Konzen et al. (1997) verificaram que 55 a 60 t de águas residuárias de suinocultura equivalem, com base na quantidade de nutrientes, a uma tonelada de adubo químico (fórmula 9-3312 + uréia); sendo assim, seriam necessárias 17 a $18 \mathrm{t} \mathrm{ha}^{-1} \mathrm{de}$ adubo orgânico, para uma fertilização equivalente à adubação química normalmente recomendada para o milho.

Chateaubriand (1988) verificou que a aplicação de água residuária de suinocultura por meio de sistema de irrigação por sulcos, em terreno de baixada com solo de textura argiloarenosa, na região de Ponte Nova, $\mathrm{MG}$, propiciou produtividade de até $8.766 \mathrm{~kg} \mathrm{ha}^{-1}$ de milho, alcançada com dosagem de $149 \mathrm{~m}^{3} \mathrm{ha}^{-1}$, produtividade cerca de $40 \%$ superior à obtida com a testemunha. A aplicação de águas residuárias de suinocultura também aumentou a altura de plantas em $19 \%$ e o peso de espigas em $65 \%$, comparativamente à testemunha. As águas residuárias foram aplicadas em dez irrigações efetuadas durante o ciclo da cultura.

Gomes (1995) avaliou o efeito da aplicação de adubo orgânico nas dosagens de $0,10,20$ e $40 \mathrm{~m}^{3} \mathrm{ha}^{-1}$, e de adubo mineral 4-14-8, nas doses de 0,250 e $500 \mathrm{~kg} \mathrm{ha}^{-1}$, sobre os componentes de produção do milho e verificou que o uso de doses maiores dos adubos orgânico e mineral contribuiu para aumentar a quantidade de nutrientes disponíveis às plantas, resultando em aumento significativo da altura de plantas e do índice de espigas. Verificou, também, que não houve diferença significativa no rendimento da cultura quando se associou composto orgânico e adubo mineral.

Este trabalho foi desenvolvido com o objetivo de se avaliar o efeito da aplicação de quatro lâminas de água e águas residuárias de suinocultura, bruta e peneirada, nos componentes de produção da cultura do milho (Zea mays L.) para silagem.

\section{MATERIAL E MÉTODOS}

Os ensaios foram conduzidos na Área Experimental de Hidráulica, Irrigação e Drenagem do Departamento de Engenharia Agrícola da Universidade Federal de Viçosa (UFV) em Viçosa, MG.

Numa faixa de terreno foram instalados 24 lisímetros de percolação, posicionados de forma emparelhada, eqüidistantes $0,60 \mathrm{~m}$ no sentido longitudinal e $0,40 \mathrm{~m}$ no sentido transversal (Figura 1). Os lisímetros foram construídos com caixas de amianto e capacidade nominal de $1 \mathrm{~m}^{3}$, medindo $1,09 \mathrm{~m}$ de largura por $1,59 \mathrm{~m}$ de comprimento na borda superior e $0,71 \mathrm{~m}$ de profundidade. A rede de drenagem se compunha por tubos de PVC de $25 \mathrm{~mm}$ de diâmetro, dotados de pequenas perfurações, e por camadas de brita zero e areia lavada. A densidade média do solo dos lisímetros foi de $1,11 \mathrm{~kg} \mathrm{dm}^{-3}$. A estação de coleta do fluido drenado foi instalada numa cota inferior à do fundo dos lisímetros.

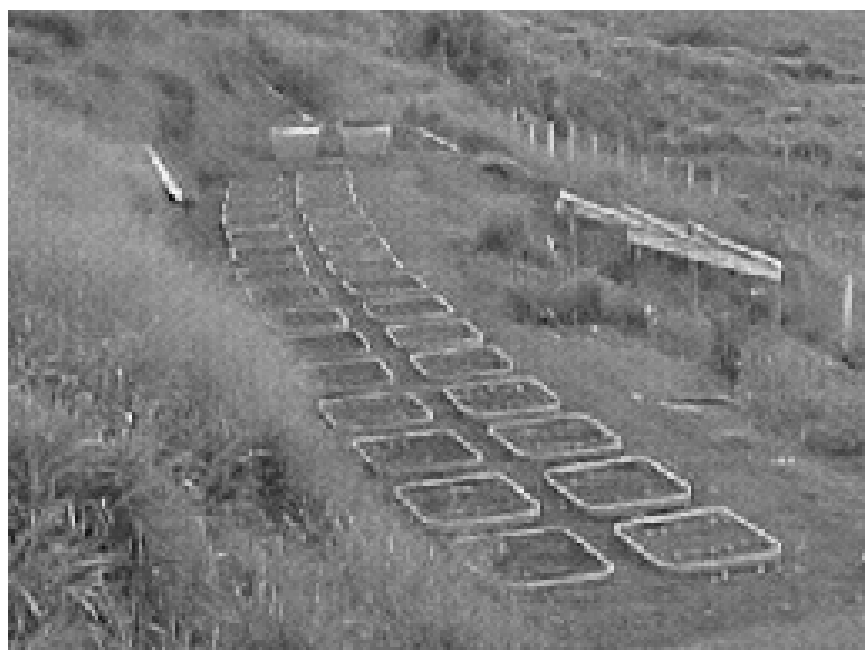

Figura 1. Vista dos lisímetros instalados no campo

O experimento foi montado segundo um esquema fatorial $3 \times 4$ (três tipos de água e 4 lâminas aplicadas) no delineamento experimental inteiramente casualizado, com duas repetições. Instalaram-se 24 lisímetros de percolação, sendo que em 8 deles se aplicou água (A), em outros 8, água residuária bruta (ARB), e nos demais água residuária peneirada (ARP). As lâminas aplicadas correspondiam a $0,5,1,0,1,5$ e 2,0ET , doravante denominadas $\mathrm{L}_{1}, \mathrm{~L}_{2}, \mathrm{~L}_{3}$ e $\mathrm{L}_{4}$, respectivamente.

Os dados foram analisados através de análise de variância e as médias foram comparadas aplicando-se o teste de Tukey a nível de $5 \%$ de probabilidade.

A ETo foi estimada por meio do método do tanque Classe A, usando-se coeficientes do tanque $\left(\mathrm{K}_{t}\right)$ recomendados por Doorenbos \& Pruitt (1977). Os dados de evaporação, umidade relativa do ar, velocidade do vento e precipitação foram coletados numa estação meteorológica localizada próximo ao experimento.

Antes e após a realização dos ensaios foram retiradas amostras de solo dos lisímetros para caracterização físicohídrica e química ao longo do perfil. Antes do plantio mantevese o solo com umidade próxima à capacidade de campo, para proceder ao balanço hídrico.

O experimento foi conduzido com milho híbrido duplo AG1051, plantado no dia 1 de junho de 2000, com espaçamentos $0,18 \times 0,80 \mathrm{~m}$. No plantio todos os tratamentos receberam adubação química à base de NPK, com formulação 4:14:8, na dosagem de $800 \mathrm{~kg} \mathrm{ha}^{-1}$. Nos tratamentos que receberam água, foram feitas duas coberturas nitrogenadas de $30 \mathrm{~kg} \mathrm{ha}^{-1} \mathrm{de} \mathrm{N}$, aos 60 e aos 90 dias após o plantio (dap). Desbastes foram realizados para se estabelecer um estande de doze plantas por lisímetro ( 70.000 plantas ha $\left.^{-1}\right)$. O controle de ervas daninhas foi feito com capinas manuais enquanto o controle contra o ataque de Spodoptera frugiperda se deu com a aplicação do inseticida piretróide "Decis", na dosagem de $0,3 \mathrm{~L} \mathrm{ha}^{-1}$.

A água usada no experimento provinha de um lago e a água residuária de suinocultura foi oriunda do setor de suinocultura da UFV, sendo armazenada em caixas de amianto, um dia antes da aplicação nas parcelas. No peneiramento da água residuária usou-se tela com malha de 16 mesh. 
O turno de rega foi de 7 dias, considerando-se as características do solo, da cultura e do clima. As parcelas experimentais receberam apenas água durante as cinco semanas iniciais, sendo os tratamentos aplicados a partir da sexta semana.

Aos 57, 109 e 137 dap retiraram-se amostras das águas aplicadas e lixiviadas nos lisímetros, para determinação do $\mathrm{pH}$, da condutividade elétrica (CE) e dos teores de N, P, K, Ca, Mg, $\mathrm{Na}, \mathrm{Zn}, \mathrm{Cu}$ e Fe. No caso das águas residuárias, foram feitas também determinações de $\mathrm{DBO}_{5}$ e DQO, além da percentagem de sólidos totais, fixos e voláteis. Na determinação dos valores de $\mathrm{DBO}_{5}$ e DQO aplicaram-se metodologias descritas em Silva (1977).

A colheita ocorreu aos 140 dap, quando as espigas de milho apresentavam características adequadas para silagem com grãos no estádio pré-farináceo. A altura da planta foi medida entre o nível do solo e a inserção da folha bandeira; a altura de espiga foi a distância vertical entre o nível do solo e a inserção da espiga. Os componentes altura de plantas e altura de espigas foram obtidos por média aritmética de todas as plantas de cada tratamento. $\mathrm{O}$ índice de espigas se obteve pela relação entre o número de espigas e o número de plantas em cada tratamento.

O corte foi feito manualmente, a $5 \mathrm{~cm}$ do solo. Todo o material colhido em cada lisímetro foi pesado, ensacado e picado, retirando-se-lhes amostras representativas de cada tratamento, as quais foram acondicionadas em "freezer". Posteriormente, foram retiradas e acondicionadas em sacos de papel, devidamente identificados, que foram colocados em estufa com circulação a ar, regulada em $65^{\circ} \mathrm{C}$, até atingir peso constante; em seguida, as amostras foram trituradas em moinho tipo "Willey" e armazenadas em saquinhos de papel, para posterior determinação do teor de matéria seca, dos níveis de proteína bruta (\% de $\mathrm{N}$ x 6,25), amônio, nitrato e fósforo (espectrofotômetro), potássio e sódio (fotômetro de chama), cálcio, magnésio, zinco, cobre e ferro (espectrofotômetro de absorção atômica), seguindo-se metodologias descritas em Silva (1977).

\section{RESULTADOS E DISCUSSÃO}

As lâminas totais aplicadas nos quatro níveis estudados, foram: $\mathrm{L}_{1}=153, \mathrm{~L}_{2}=280, \mathrm{~L}_{3}=416 \mathrm{e}_{4}=556 \mathrm{~mm}$ de água e águas residuárias de suinocultura.

$\mathrm{Na}$ Tabela 1 apresenta-se a caracterização química da água e das águas residuárias aplicadas nos lisímetros, em três épocas, ao longo do ciclo da cultura.
Os valores de concentração dos nutrientes estão dentro da faixa de variação encontrada em diversos trabalhos com águas residuárias de suinocultura (Queiroz, 2000).

As concentrações médias de sódio nos tratamentos com água, ARB e ARP foram 9,8, 112,3 e 106,1 mg L-1, respectivamente. $\mathrm{O}$ valor médio de $\mathrm{pH}$ da água foi $6,6 \mathrm{e} \mathrm{a} \mathrm{CE}$ foi igual a $0,2 \mathrm{dS} \mathrm{m}^{-1}$; para as águas residuárias os valores foram 7,5 e 5,5 $\mathrm{dS} \mathrm{m}^{-1}$, respectivamente. As concentrações de sólidos sedimentáveis, sólidos totais e $\mathrm{DBO}_{5}$ foram 114,7, 1.235,0 e 1.111,0 $\mathrm{mg} \mathrm{L}^{-1}$ para ARB e 75,2, 506,0 e 1.072,0 $\mathrm{mg} \mathrm{L}^{-1}$ para ARP, respectivamente.

$\mathrm{Na}$ Tabela 2 tem-se os resultados médios das análises químicas do solo, determinadas em amostras coletadas na camada de 0 a $50 \mathrm{~cm}$ de profundidade, antes e após o período experimental, e sua classificação, segundo a Comissão de Fertilidade do Solo do Estado de Minas Gerais (CFSEMG, 1999).

O solo usado no preenchimento dos lisímetros foi proveniente de horizonte B, apresentando baixa fertilidade.

De acordo com a CFSEMG (1999) os elementos P, K, Ca, $\mathrm{Mg}$ e Al foram distribuídos em cinco classes de interpretação da disponibilidade: muito baixo, baixo, médio, bom e muito bom. Os micronutrientes $\mathrm{Fe}, \mathrm{Cu}$ e $\mathrm{Zn}$ foram classificados de acordo com sua disponibilidade, nos níveis muito baixo, baixo, médio, bom e alto.

Na Tabela 2 observa-se que os valores de $\mathrm{pH}$ permaneceram praticamente inalterados com a adição de águas residuárias de suinocultura. Os níveis de $\mathrm{P}, \mathrm{K}, \mathrm{Na}, \mathrm{Ca}, \mathrm{Mg}, \mathrm{Cu}$ e $\mathrm{Zn}$ no solo aumentaram com a aplicação de águas residuárias de suinocultura, por se tratar de fonte rica nesses nutrientes. No entanto, deve-se atentar para o risco de salinização e de alteração na capacidade de infiltração da água no solo, relacionada ao aumento da razão de adsorção de sódio. A acidez trocável do solo $\left(\mathrm{Al}^{3+}\right)$ decresceu com a aplicação de águas residuárias devido, provavelmente, ao maior valor de $\mathrm{pH}$ dessas águas. $\mathrm{O}$ nível de Fe praticamente não foi alterado.

$\mathrm{Na}$ Tabela 3 estão apresentados os valores das análises químicas dos efluentes coletados dos lisímetros, em três épocas após o plantio, para os tipos de água e lâminas aplicadas.

Analisando-se a Tabela 3, observa-se que a concentração de amônio foi maior nos tratamentos que receberam águas residuárias. Nesses tratamentos, as maiores concentrações ocorreram quando foram aplicadas maiores lâminas, principalmente nos períodos mais avançados do ciclo da cultura, em decorrência da aplicação de doses sucessivas em quantidades

Tabela 1. Caracterização química dos três tipos de água aplicada nos lisímetros, em três épocas ao longo do ciclo da cultura

\begin{tabular}{|c|c|c|c|c|c|c|c|c|c|c|c|c|}
\hline \multirow{3}{*}{ Trat. } & \multicolumn{12}{|c|}{ Concentração do Nutriente Aplicado* } \\
\hline & \multicolumn{3}{|c|}{ Amônio (mg L L $\left.{ }^{-1}\right)$} & \multicolumn{3}{|c|}{ Nitrato $\left(\mathrm{mg} \mathrm{L}^{-1}\right)$} & \multicolumn{3}{|c|}{$\mathrm{P}\left(\mathrm{mg} \mathrm{L}^{-1}\right)$} & \multicolumn{3}{|c|}{$\mathrm{K}\left(\mathrm{mg} \mathrm{L}^{-1}\right)$} \\
\hline & 57 dap & 109 dap & 137 dap & 57 dap & 109 dap & 137 dap & 57 dap & 109 dap & 137 dap & 57 dap & 109 dap & 137 dap \\
\hline A & 3,28 & 17,0 & - & 0,31 & 1,84 & - & 3,53 & 1,31 & - & 18,83 & 9,16 & - \\
\hline $\mathrm{ARB}$ & 5007 & 3423 & 3455 & 3,40 & 3,80 & 17,82 & 76,46 & 86,85 & 38,91 & 715,5 & 533,5 & 837,9 \\
\hline ARP & 5216 & 4238 & 4107 & 4,24 & 7,92 & 12,86 & 75,01 & 70,50 & 34,90 & 819,3 & 555,8 & 859,6 \\
\hline \multirow{2}{*}{ Trat. } & \multicolumn{3}{|c|}{$\mathrm{Ca}\left(\mathrm{mg} \mathrm{L}^{-1}\right)$} & \multicolumn{3}{|c|}{$\operatorname{Mg}\left(\mathrm{mg} \mathrm{L}^{-1}\right)$} & \multicolumn{3}{|c|}{$\mathrm{Cu}\left(\mathrm{mg} \mathrm{L}^{-1}\right)$} & \multicolumn{3}{|c|}{$\mathrm{Zn}\left(\mathrm{mg} \mathrm{L}^{-1}\right)$} \\
\hline & 57 dap & 109 dap & 137 dap & 57 dap & 109 dap & 137 dap & 57 dap & 109 dap & 137 dap & 57 dap & 109 dap & 137 dap \\
\hline $\mathrm{A}$ & - & 12,5 & - & - & 1,35 & - & 0,004 & 0,025 & - & 0,0026 & 0,012 & - \\
\hline $\mathrm{ARB}$ & - & 382,1 & 714,9 & - & 48,6 & 57,3 & 0,974 & 1,710 & 2,020 & 7,01 & 19,03 & 31,51 \\
\hline ARP & - & 340,5 & 802,0 & - & 50,2 & 65,1 & 0,738 & 1,266 & 2,150 & 5,19 & 20,23 & 24,57 \\
\hline
\end{tabular}

*dap - dia após o plantio; A - água; ARB - água residuária bruta; ARP - água residuária peneirada 
Tabela 2. Características químicas do solo ${ }^{1}$ da camada de 0 a $50 \mathrm{~cm}$ de profundidade, antes (testemunha) e depois da aplicação de água (A) e das águas residuárias bruta (ARB) e peneirada (ARP), e sua classificação segundo a CFSEMG (1999)

\begin{tabular}{|c|c|c|c|c|c|c|c|c|c|c|}
\hline \multirow{3}{*}{ Tratamento } & \multicolumn{10}{|c|}{ Características Químicas } \\
\hline & \multirow{2}{*}{$\mathrm{pH}$} & $\mathrm{P}$ & $\mathrm{K}$ & $\mathrm{Na}$ & $\mathrm{Ca}$ & $\mathrm{Mg}$ & $\mathrm{Al}$ & $\mathrm{Fe}$ & $\mathrm{Cu}$ & $\mathrm{Zn}$ \\
\hline & & \multicolumn{3}{|c|}{$\mathrm{mg} \mathrm{dm}^{-3}$} & \multicolumn{3}{|c|}{$\mathrm{cmol}_{\mathrm{c}} \mathrm{dm}^{-3}$} & \multicolumn{3}{|c|}{$\mathrm{mg} \mathrm{dm}^{-3}$} \\
\hline A & $\begin{array}{c}5,1 \\
\text { acidez } \\
\text { média }\end{array}$ & $\begin{array}{c}3,8 \\
\text { baixo }\end{array}$ & $\begin{array}{c}21,5 \\
\text { baixo }\end{array}$ & 6,2 & $\begin{array}{c}0,42 \\
\text { baixo }\end{array}$ & $\begin{array}{c}0,06 \\
\text { muito } \\
\text { baixo }\end{array}$ & $\begin{array}{c}0,53 \\
\text { médio }\end{array}$ & $\begin{array}{l}53,7 \\
\text { alto }\end{array}$ & $\begin{array}{l}1,29 \\
\text { bom }\end{array}$ & $\begin{array}{l}1,90 \\
\text { bom }\end{array}$ \\
\hline $\mathrm{ARB}$ & $\begin{array}{c}5,5 \\
\text { acidez } \\
\text { média }\end{array}$ & $\begin{array}{c}115,0 \\
\text { muito } \\
\text { bom }\end{array}$ & $\begin{array}{c}143,5 \\
\text { Muito } \\
\text { bom }\end{array}$ & 38,1 & $\begin{array}{c}1,62 \\
\text { médio }\end{array}$ & $\begin{array}{c}0,42 \\
\text { baixo }\end{array}$ & $\begin{array}{c}0,15 \\
\text { muito } \\
\text { baixo }\end{array}$ & $\begin{array}{l}46,3 \\
\text { alto }\end{array}$ & $\begin{array}{l}2,85 \\
\text { alto }\end{array}$ & $\begin{array}{c}16,30 \\
\text { alto }\end{array}$ \\
\hline ARP & $\begin{array}{c}5,4 \\
\text { acidez } \\
\text { média }\end{array}$ & $\begin{array}{c}79,1 \\
\text { muito } \\
\text { bom }\end{array}$ & $\begin{array}{c}149,5 \\
\text { muito } \\
\text { bom }\end{array}$ & 38,4 & $\begin{array}{c}1,33 \\
\text { médio }\end{array}$ & $\begin{array}{c}0,37 \\
\text { baixo }\end{array}$ & $\begin{array}{c}0,20 \\
\text { muito } \\
\text { baixo }\end{array}$ & $\begin{array}{l}54,3 \\
\text { alto }\end{array}$ & $\begin{array}{c}2,44 \\
\text { alto }\end{array}$ & $\begin{array}{c}13,10 \\
\text { alto }\end{array}$ \\
\hline
\end{tabular}

${ }^{1} \mathrm{pH}$ em água - Relação 1:2,5; Ca-Mg-Al - extrator $\mathrm{KCl}-1$ mol L-1; P-K-Na-Fe-Zn-Cu - extrator de Mehlich 1

Tabela 3. Caracterização físico-química do lixiviado dos lisímetros, em três épocas ao longo do ciclo da cultura, para diversos tratamentos aplicados

\begin{tabular}{|c|c|c|c|c|c|c|c|c|c|c|c|c|}
\hline \multirow{3}{*}{ Efluente } & \multicolumn{12}{|c|}{ Concentração de Nutrientes no Efluente ${ }^{2}$} \\
\hline & \multicolumn{3}{|c|}{ Amônio (mg L'-1) } & \multicolumn{3}{|c|}{ Nitrato $\left(\mathrm{mg} \mathrm{L}^{-1}\right)$} & \multicolumn{3}{|c|}{$\mathrm{P}\left(\mathrm{mg} \mathrm{L}^{-1}\right)$} & \multicolumn{3}{|c|}{$\mathrm{K}\left(\mathrm{mg} \mathrm{L}^{-1}\right)$} \\
\hline & 57 dap & 109 dap & 137 dap & 57 dap & 109 dap & 137 dap & 57 dap & 109 dap & 137 dap & 57 dap & 109 dap & 137 dap \\
\hline A L3 & 9,8 & 15,7 & - & 5,37 & 3,37 & - & 0,24 & 0,74 & - & 298,9 & 31,5 & - \\
\hline A L4 & 3,3 & 16,6 & - & 8,97 & 3,00 & - & 0,91 & 0,31 & - & 226,5 & 29,6 & - \\
\hline ARB L3 & 3,3 & 170,8 & 886,7 & 4,53 & 7,02 & 6,77 & 0,14 & 1,14 & 1,44 & 290,5 & 68,7 & 584,8 \\
\hline ARP L3 & 16,3 & 208,6 & 658,5 & 5,22 & 7,76 & 5,83 & 0,33 & 0,53 & 1,88 & 353,3 & 182,1 & 490,8 \\
\hline ARP L4 & 32,6 & 504,6 & 769,3 & 7,22 & 9,24 & 10,39 & 0,33 & 0,36 & 0,60 & 468,0 & 440,5 & 428,6 \\
\hline \multirow{2}{*}{ Efluente } & \multicolumn{3}{|c|}{$\mathrm{Ca}\left(\mathrm{mg} \mathrm{L}^{-1}\right)$} & \multicolumn{3}{|c|}{$\operatorname{Mg}\left(\mathrm{mg} \mathrm{L}^{-1}\right)$} & \multicolumn{3}{|c|}{$\mathrm{Cu}\left(\mathrm{mg} \mathrm{L}^{-1}\right)$} & \multicolumn{3}{|c|}{$\mathrm{Zn}\left(\mathrm{mg} \mathrm{L}^{-1}\right)$} \\
\hline & 57 dap & 109 dap & 137 dap & 57 dap & 109 dap & 137 dap & 57 dap & 109 dap & 137 dap & 57 dap & 109 dap & 137 dap \\
\hline A L2 & - & 33,5 & - & - & 1,50 & - & 0,004 & 0,043 & - & 0 & 0,017 & - \\
\hline ARB L4 & - & 313,8 & 263,9 & - & 25,4 & 31,5 & 0,009 & 0,049 & 0,090 & 0,330 & 0,182 & 0,358 \\
\hline ARP L2 & - & - & - & - & - & - & 0,006 & - & - & 0 & - & - \\
\hline ARP L3 & - & 411,9 & 347,7 & - & 24,4 & 28,2 & 0,007 & 0,089 & 0,089 & 0,002 & 0,051 & 0,453 \\
\hline ARP L4 & - & 375,3 & 471,3 & - & 32,0 & 44,2 & 0,007 & 0,071 & 0,108 & 0,110 & 0,254 & 0,397 \\
\hline
\end{tabular}

${ }^{2}$ Não ocorreu percolação nos tratamentos com lâminas de $0,5 \mathrm{ET}_{0}$ (L1) ou com $1,0 \mathrm{ET}_{0}$ (L2). Nos outros casos ocorreram problemas que impossibilitaram a análise.

A - água; ARB - água residuária bruta; ARP - água residuária peneirada

$\mathrm{L} 1=0,5 \mathrm{ETo} ; \mathrm{L} 2=1,0 \mathrm{ETo} ; \mathrm{L} 3=1,5 \mathrm{ETo} ; \mathrm{L} 4=2,0 \mathrm{ETo}$

superiores à capacidade de retenção do solo e de extração pela cultura. A concentração de nitrato excedeu os padrões de potabilidade de $10 \mathrm{mg} \mathrm{L}^{-1}$ no final do ciclo da cultura (137 dap), para a maior lâmina aplicada nos tratamentos com águas residuárias (ARB L4 e ARP L4), indicando grande risco de contaminação de águas subterrâneas decorrentes de plantios subseqüentes.

Embora as águas residuárias aplicadas fossem ricas em fósforo, ocorreu pequena concentração desse nutriente no lixiviado dos lisímetros, em decorrência de sua baixa mobilidade no solo, ficando grande parte retida na camada de 0 a $50 \mathrm{~cm}$ de profundidade, como pode ser observado na Tabela 2 . A concentração de potássio no lixiviado dos tratamentos com águas residuárias aumentou quando se aplicaram maiores lâminas. Os menores valores foram observados aos 109 dap, coincidindo com os períodos de maior absorção deste nutriente pela cultura do milho.

As concentrações de $\mathrm{Ca}$ e $\mathrm{Mg}$ presentes nos lixiviados dos lisímetros com aplicação de águas residuárias, geralmente foram menores que os valores encontrados nos afluentes (Tabela 1) principalmente aos 137 dap, indicando expressiva retenção desses cátions no solo e sua absorção pelas plantas. As maiores concentrações de $\mathrm{Cu}\left(0,200 \mathrm{mg} \mathrm{L}^{-1}\right)$ e $\mathrm{Zn}\left(0,453 \mathrm{mg} \mathrm{L}^{-1}\right)$ observadas nos lixiviados dos lisímetros estão abaixo dos padrões de lançamento desses elementos em corpos d'água, iguais a 0,5 e $5,0 \mathrm{mg} \mathrm{L}^{-1}$, respectivamente.

$\mathrm{Na}$ Tabela 4 estão apresentados os resumos das análises de variância dos dados de alturas de planta e espiga (m), índice de espiga e produtividades de espiga, matéria verde e matéria seca $\left(\mathrm{t} \mathrm{ha}^{-1}\right)$. 
Tabela 4. Análise de variância dos componentes de produção altura de planta (AP), altura de espiga (AE), índice de espiga (IE), produtividade de espiga (PE), produtividade de matéria verde (PMV) e produtividade de matéria seca (PMS)

\begin{tabular}{|c|c|c|c|c|c|c|c|}
\hline \multirow{2}{*}{ FV } & \multirow{2}{*}{ GL } & \multicolumn{6}{|c|}{ QM } \\
\hline & & AP & $\mathrm{AE}$ & IE & PE & PMV & PMS \\
\hline Tipo de Água (TA) & 2 & $0,3113 * *$ & $0,1568 * *$ & $0,2543 * *$ & $298,033 * *$ & $1477,697 * *$ & $155,863 * *$ \\
\hline Lâmina (L) & 3 & $0,0173^{\mathrm{ns}}$ & $0,00155^{\mathrm{ns}}$ & $0,0089^{\mathrm{ns}}$ & $20,609^{\mathrm{ns}}$ & $166,719^{\mathrm{ns}}$ & $5,6212^{\mathrm{ns}}$ \\
\hline Resíduo & 12 & 0,0388 & 0,0136 & 0,0208 & 13,939 & 60,568 & $5,4812^{\mathrm{ns}}$ \\
\hline $\mathrm{CV}$ & & 12,82 & 13,03 & 15,52 & 25,25 & 20,64 & 22,183 \\
\hline
\end{tabular}

** Significativo a $1 \%$ de probabilidade pelo teste $\mathrm{F}$; ns - não-significativo a $5 \%$ de probabilidade pelo teste $\mathrm{F}$

Os resultados mostraram efeito significativo apenas para tipo de água aplicada, a nível de $1 \%$ de probabilidade. A água residuária de suinocultura é, sabidamente, fonte rica em diversos nutrientes necessários ao desenvolvimento das plantas e, mesmo aplicada em grandes quantidades na cultura do milho, não resultou em fitotoxicidade capaz de afetar negativamente os componentes de produção, considerandose apenas um plantio. No entanto, há de se considerar o elevado potencial de contaminação de águas subterrâneas quando aplicada em doses elevadas, como verificado na análise química dos lixiviados dos lisímetros (Tabela 3).

A Tabela 5 apresenta os valores médios dos componentes de produção para os três tipos de água utilizados no experimento.

A análise da Tabela 5 mostra que as aplicações de águas residuárias aumentaram os valores de todos os componentes de produção da cultura do milho, comparativamente à testemunha, sendo esses aumentos significativos na maioria dos casos. Comparando-se os dois tipos de água residuária observa-se que o peneiramento não afetou nenhum componente de produção.

Em relação à altura de planta e altura de espiga, verifica-se que os tratamentos não diferiram estatisticamente a nível de $5 \%$ de probabilidade, à exceção da lâmina $0,5 \mathrm{ETo}\left(\mathrm{L}_{1}\right)$. Apesar disso, observa-se considerável aumento desses componentes nos tratamentos que receberam aplicação de águas residuárias de suinocultura. Em média, as alturas de plantas nos tratamentos que receberam ARB e ARP foram 21 e $20 \%$ superiores à testemunha, respectivamente. Para altura de espiga, os valores foram da ordem de 26 e $24 \%$ superiores à testemunha, respectivamente.

Em geral, maiores valores do IE foram observados nos tratamentos que receberam águas residuárias. Os valores observados do IE para os tratamentos com aplicações das lâminas intermediárias $\left(\mathrm{L}_{2} \mathrm{e} \mathrm{L}_{3}\right)$ foram estatisticamente iguais; em média, os índices de espiga nos tratamentos que receberam os dois tipos de águas residuárias foram $30 \%$ superiores à testemunha. Nos tratamentos que receberam aplicações de águas residuárias de suinocultura o IE foi maior que 1, indicando que havia mais espigas que plantas, condição ideal para fins de silagem.

Os valores encontrados para PE nos tratamentos com águas residuárias foram aproximadamente iguais aos encontrados para a testemunha; no entanto, em alguns casos, não houve diferença estatística. Para a maior lâmina aplicada $\left(\mathrm{L}_{4}\right)$ os dois tratamentos com aplicação de água residuária foram estatisticamente iguais entre si e superiores à testemunha. Em média, a
Tabela 5. Valores médios dos componentes de produção AP, AE, IE, PE, PMV e PMS obtidos nos ensaios experimentais com água (A), água residuária bruta (ARB) e água residuária peneirada (ARP) para as diferentes lâminas aplicadas*

\begin{tabular}{cccccc}
$\begin{array}{c}\text { Tipo } \\
\text { de água }\end{array}$ & $\mathrm{L}_{1}$ & $\mathrm{~L}_{2}$ & $\mathrm{~L}_{3}$ & $\mathrm{~L}_{4}$ & Médias \\
\hline \multicolumn{7}{c}{ AP $(\mathrm{m})$} \\
A & $1,159 \mathrm{a}$ & $1,386 \mathrm{a}$ & $1,497 \mathrm{a}$ & $1,199 \mathrm{a}$ & 1,31 \\
ARB & $1,717 \mathrm{~b}$ & $1,674 \mathrm{a}$ & $1,636 \mathrm{a}$ & $1,622 \mathrm{a}$ & 1,66 \\
ARP & $1,557 \mathrm{ab}$ & $1,671 \mathrm{a}$ & $1,633 \mathrm{a}$ & $1,699 \mathrm{a}$ & 1,64 \\
\hline \multicolumn{7}{c}{ AE $(\mathrm{m})$} \\
A & $0,693 \mathrm{a}$ & $0,728 \mathrm{a}$ & $0,801 \mathrm{a}$ & $0,711 \mathrm{a}$ & 0,73 \\
ARB & $1,033 \mathrm{~b}$ & $0,976 \mathrm{a}$ & $0,967 \mathrm{a}$ & $0,984 \mathrm{a}$ & 0,99 \\
ARP & $0,888 \mathrm{ab}$ & $0,995 \mathrm{a}$ & $0,960 \mathrm{a}$ & $0,991 \mathrm{a}$ & 0,96 \\
\hline \multicolumn{7}{c}{$\mathrm{IE}$} \\
A & $0,627 \mathrm{a}$ & $0,750 \mathrm{a}$ & $0,864 \mathrm{a}$ & $0,650 \mathrm{a}$ & 0,72 \\
ARB & $1,063 \mathrm{~b}$ & $1,036 \mathrm{a}$ & $1,031 \mathrm{a}$ & $1,000 \mathrm{ab}$ & 1,03 \\
ARP & $1,000 \mathrm{ab}$ & $1,042 \mathrm{a}$ & $1,036 \mathrm{a}$ & $1,046 \mathrm{~b}$ & 1,03 \\
\hline \multicolumn{7}{c}{ PE $\left(\mathrm{t} \mathrm{ha} \mathrm{a}^{-1}\right)$} \\
A & $6,188 \mathrm{a}$ & $8,954 \mathrm{a}$ & $10,207 \mathrm{a}$ & $5,614 \mathrm{a}$ & 7,74 \\
ARB & $16,416 \mathrm{~b}$ & $16,541 \mathrm{ab}$ & $19,424 \mathrm{a}$ & $21,011 \mathrm{~b}$ & 18,35 \\
ARP & $13,667 \mathrm{ab}$ & $19,906 \mathrm{~b}$ & $19,048 \mathrm{a}$ & $20,488 \mathrm{~b}$ & 18,28 \\
\hline \multicolumn{7}{c}{ PMV (t ha $\left.{ }^{-1}\right)$} \\
A & $18,724 \mathrm{a}$ & $24,288 \mathrm{a}$ & $26,475 \mathrm{a}$ & $18,597 \mathrm{a}$ & 22,02 \\
ARB & $39,662 \mathrm{~b}$ & $40,100 \mathrm{ab}$ & $48,653 \mathrm{~b}$ & $51,587 \mathrm{~b}$ & 45,00 \\
ARP & $31,726 \mathrm{ab}$ & $51,012 \mathrm{~b}$ & $49,335 \mathrm{~b}$ & $52,263 \mathrm{~b}$ & 46,08 \\
\hline \multicolumn{7}{c}{ PMS (t ha $\left.{ }^{-1}\right)$} \\
A & $4,909 \mathrm{a}$ & $5,854 \mathrm{a}$ & $6,464 \mathrm{a}$ & $4,629 \mathrm{a}$ & 5,45 \\
ARB & $9,955 \mathrm{ab}$ & $12,220 \mathrm{~b}$ & $14,058 \mathrm{~b}$ & $14,420 \mathrm{~b}$ & 13,33 \\
ARP & $12,628 \mathrm{~b}$ & $13,825 \mathrm{~b}$ & $13,361 \mathrm{~b}$ & $14,322 \mathrm{~b}$ & 12,87 \\
\hline
\end{tabular}

*AP - Altura de planta; AE - Altura de espiga; IE - Indice de espiga; PE - Produtividade de espiga PMV - Produtividade de materia verde ; PMS - Produtividade matéria seca. Dentro da mesma coluna, as médias com mesma letra não diferem, a $5 \%$ de probabilidade, pelo teste Tukey

PE foi $58 \%$ superior à testemunha para os tratamentos que receberam ARB e ARP.

Os resultados mostraram que a PMV foi maior nos tratamentos que receberam águas residuárias, com produtividades médias de 45 e $46 \mathrm{t} \mathrm{ha}^{-1}$ para ARB e ARP, respectivamente. Comportamento semelhante foi observado para PMS, com produtividade média em torno de $13 \mathrm{t} \mathrm{ha}^{-1}$ para ARB e ARP. Almeida Filho (1996), em experimento com cultivares de milho para silagem, obteve PMS variando de 9,62 a 14,37 tha ${ }^{-1}$, sendo a maior produtividade obtida para a cultivar AG 1051. Flaresso et al. (1999) obtiveram PMS variando de 14,09 a 18,66 tha-1, ao longo de três safras na região de Santa Catarina, sendo a maior produtividade também obtida com a cultivar AG 1051.

Com a aplicação de lâminas excessivas buscou-se avaliar o efeito na cultura do milho resultante da prática corrente de disposição de grande quantidade de água residuária de 
suinocultura no solo, sobretudo em pequenas propriedades rurais. Apesar da tendência de aumento da PMV com a aplicação de lâminas maiores, não houve efeito significativo da lâmina sobre os componentes de produção (Tabela 4).

A menor lâmina (0,5ETo) não foi suficiente para provocar lixiviação de sais na profundidade de $50 \mathrm{~cm}$ (Tabela 3 ), reduzindo o risco de contaminação de águas subterrâneas. Do ponto de vista ambiental, ela pode ser considerada a menos problemática dentre as lâminas aplicadas, por ter associado este fato ao aumento significativo da produtividade de matéria verde comparativamente à testemunha (ARB); seu uso deve estar condicionado à complementação da lâmina necessária à cultura por meio de chuva ou de sistema de irrigação, associada à drenagem adequada da área cultivada e possível reuso da água na agricultura.

Os baixos valores dos componentes de produção nos tratamentos com água foram ocasionados por deficiência de alguns nutrientes no solo. Neste caso, a partir da segunda metade do ciclo a cultura apresentava folhas com clorose e necrose nas margens, além de colmos finos, evidenciando deficiência de K. Observaram-se, também, problemas de atraso no florescimento e má granação, afetando o peso e o índice de espigas, associado à deficiência de $\mathrm{P}$ no solo, além de ausência de espigas em plantas adultas nos tratamentos com água, indicativo de deficiência de $\mathrm{Zn}$.

\section{CONCLUSÕES}

1. As aplicações de águas residuárias bruta e peneirada aumentaram a produtividade de matéria verde, comparativamente à aplicação de água, com valores médios de 45 e 46 tha $^{-1}$, cerca de 51 e $52 \%$ superiores à testemunha, respectivamente. A produtividade de matéria seca foi de $13 \mathrm{t} \mathrm{ha}^{-1}$ para os dois tipos de água.

2. A aplicação de águas residuárias de suinocultura aumentou os valores de altura de plantas, índice de espigas, altura de espigas e peso de espigas do milho.
3. O peneiramento da água residuária e as diferentes lâminas aplicadas não afetaram os parâmetros de produção do milho para silagem.

4. A menor lâmina aplicada (0,5ETo) não foi suficiente para ocasionar percolação na profundidade de $50 \mathrm{~cm}$ de profundidade, apresentando menor risco de contaminação de águas subterrâneas comparativamente às demais lâminas aplicadas.

\section{LITERATURA CITADA}

Almeida Filho, S.L. Avaliação de cultivares de milho (Zea mays L.) para silagem. Viçosa: UFV, 1996. 53p. Tese Mestrado

CFSEMG, Comissão de Fertilidade do Solo do Estado de Minas Gerais. Recomendação para uso de corretivos e fertilizantes em Minas Gerais: 5 aproximação. Lavras, 1999. 176p.

Chateaubriand, A.D. Efeito de dejetos de suínos, aplicados em irrigação por sulco, na cultura do milho (Zea mays L.). Viçosa: UFV, 1988. 61p. Tese Mestrado

Doorenbos, J.; Pruitt, W.O. Guidelines for predicting crop water requeriments. Rome, FAO, 1977. 144p. Irrigation and Drainage Paper, 24

Flaresso, J.A.; Gross, C.D.; Almeida, E.X.A. Avaliação de cultivares de milho e sorgo para ensilagem no Alto Vale do Itajaí. Agropecuária Catarinense, Florianópolis, v.12, n.3, p.39-44, 1999.

Gomes, J.A. Efeito de adubações orgânica e mineral sobre a produtividade do milho e sobre algumas características físicas e químicas de um Podzólico Vermelho-Amarelo. Viçosa: UFV, 1995. 59p. Tese Mestrado

Konzen, E.A.; Pereira Filho, I.A.; Bahia Filho, A.F.C.; Pereira, F.A. Manejo do esterco líquido de suínos e sua utilização na adubação do milho. Sete Lagoas: EMBRAPA - CNPMS, 1997. 31p. Circular Técnica, 25

Queiroz, F.M. de. Avaliação de gramíneas forrageiras para o tratamento de águas residuárias de suinocultura. Viçosa: UFV, 2000. 61p. Tese Mestrado

Silva, M.O.S.A. Análises físico-químicas para controle de estações de tratamentos de esgotos. São Paulo: CETESB, 1977.226p. 